of those who clog the institute payrolls, but who have long since ceased to be productive as researchers.

But how to decide which institutes are worth keeping, and which people have something to contribute in the years ahead? In the turbulent few years past, the Russian research enterprise has been partly shaped by what might be called market forces; research institutes able to recruit funds from outside their traditional sources of support have been able to pay their people decent salaries; others have been compelled to manage on a shoe-string. But that, even if it works, is a blunt instrument. Laboratories now prospering may owe more to the guile of their directors, or to lucky accidents, than to their potential value to Russia. A further difficulty is that the present organization of research is ill-suited to modern needs. Basic research in, say, genetics remains largely the prerogative of institutes of the academy, but clinical applications rest with the Academy of Medical Sciences. The gulf between research and the universities is a Stalinist scandal.

But Yeltsin seemed, a few weeks ago, to be hoping that competition for research grants would allow an extension of that process, allowing competent researchers to win continuing support and forcing others out. There are several snags. One is that the criteria by which research-grant applications should be judged must somehow be defined. Another is that research cannot happen in a vacuum, but requires infrastructure. A third is that the Russian research community has no experience of making honest appraisals of its own research proposals. The experience of the Soros fund, which plans to allocate $\$ 60$ million to basic research proposals in the next few months, will be enlightening, but cannot be a model for all of Russia's need.

Yeltsin (if he survives the present turmoil) should therefore bite an unpalatable bullet, and seek help in answering his question from outside Russia, both to shrink the research enterprise and to reshape it. Russian science has wellwishers enough. It should not be difficult to find a group of outside commissioners to recommend ways of shrinking and reorganizing the plethora of research institutes and then of encouraging the remaining productive core. It would be a huge task, but not an impossible one. And there are precedents. The Baltic states have sought help of just this kind from their Scandinavian neighbours. For that matter, research organizations in Germany and (now) in Japan as well seem to value external advice on their way of doing business. Why should not even Russia follow suit?

Pride is one answer. Another is that an external assessment of Russian science would be denounced by some of those adversely affected as a malign plot by, say, the US Central Intelligence Agency or some other imagined Western instrument of Russia's emasculation. The second is a powerful political argument. But it is irrelevant to the question of how to salvage something worthwhile from one of the largest and most talented components of the international research enterprise. Every political upheaval in the past few turbulent years has taken its toll of Russian science. The storming of the Russian parliament on Monday, whatever the justification, will be another setback. How many more of these crises will be needed to kill it off?

\section{India's latest earthquake}

The seismic causes of last week's tragedy are less forbidding than the ultimate cause: rural poverty.

THE real tragedy of last week's earthquake in Maharashtra State is that an event of such a magnitude (6.4) in California would not have killed 20,000 people (but the final toll in India may be even higher). Quite possibly, there would have been no deaths at all, while damage to houses and other buildings would probably have left only a small mark on the financial accounts of US insurance companies. That was the experience in 1987 of the earthquake (magnitude 6.0) near San Jose, when there were no deaths and the physical damage amounted to some $\$ 10$ million. Earthquakes as such are not especially damaging to people, who are maimed and killed by the damage done to buildings and other mechanical structures. Reports that farm animals quartered overnight in nearby fields have survived bear that out.

It is, of course, cruel bad luck that last week's earthquake should have happened in a region in which earthquakes are rare and, far away from the edges of the neighbouring tectonic plates, are expected to be rare. Most of central India, indeed, lies on Precambrian continental crust, which experience (as in the Canadian Shield) has shown to be remarkably stable against seismicity. But the Indian Plate is still being impelled northwards, into and beneath the Himalayas. The seismic trace of last week's earthquake (with a focus 20 $\mathrm{km}$ below the surface) accords with the view that the cause was a thrust fault caused by north-south compression in the plate. That is no comfort, of course, to the survivors.

Nor will it be much help to them that the Indian government's political opponents in a forthcoming state election have seized on local anxiety about a string of small earthquakes in recent years to claim that the government should have taken action sooner. It might be different if there were a better understanding of the significance of the microseisms that sometimes precede destructive earthquakes. But in any case, what could the government have done?

The reasons why so many were killed in Maharashtra last week have much longer roots than the period in which the local population has been worried by microseisms. The standard way of building houses in the region, in which rocks are embedded in adobe, is a recipe for personal disaster when earthquakes come. So why should not Maharashtra follow California in building wooden frame houses to prescribed building standards? Because India does not have all that much wood, because earthquakes are in any case uncommon in the region and because the people seeking shelter in central Maharashtra could not afford the luxury of safe housing. In short, if the proximate cause of last week's tragedy was the earthquake, its underlying cause was the continuing poverty of rural India. The question to ask is not whether the microseisms of the past few years could have been used to avoid the tragedy, but when India's new-found industrial prosperity will trickle down to relieve some of the most cruel poverty in the world. 